\title{
Chapter 4 \\ Modern Communication Technologies and the Marxist Understanding of Scientific Cognition
}

\author{
Naira Danielyan
}

\begin{abstract}
The bicentenary of the birth of Karl Marx occurred recently (2018). It is thus apposite and insightful to reconsider his theories that relate to modern developments in the field of communications technology. Marxism proposed the view that the basis of the human-specific attitude to the world is focused on practical activity directed to the transformation of natural and social objective reality. Scientific results focus on natural and social objects and processes and this blends into science-based technologies, interacting and being changed by humans who realize some objective or social activity. Communication practice is connected with definite forms of worldview and a definite level of cognition, which reflects practical achievements and promotes their further reproduction and perfection. According to Marx, primacy of practice means that the efficacy of its real influence on nature, society, and personality is a characteristic of the development of a subject's cognitive activity. It is concluded that Marxism's achievement is the development of the scheme: objectobjective-practical activity_-subject as the foundation of scientific cognition and the criterion for the correspondence between knowledge and reality. Nowadays this scheme is taken as primary while constructing and understanding communication technologies, considered as a special form of practice: this implies the dialectic unity of material artifacts on the one hand and human skills and experience on the other hand.
\end{abstract}

Keywords Co-construction • Cognition • Communication technology • Marx • Marxism $\cdot$ Object $\cdot$ Practice $\cdot$ Subject $\cdot$ Technical activity $\cdot$ Trans-humanism

\subsection{Introduction}

Humans interact with the environment in varying degrees, ranging from passivity to aggressive pursuit of possibilities to transform it actively. Active transformation can be seen as being driven by the process of personal development as a social being

\footnotetext{
N. Danielyan ( $\varangle)$

Philosophy, Sociology and Political Science Department, National Research University of Electronic Technology, Moscow, Russian Federation

e-mail: vend22@yandex.ru

(C) The Author(s) 2020

R. Earnshaw et al. (eds.), Technology, Design and the Arts-Opportunities and Challenges, Springer Series on Cultural Computing, https://doi.org/10.1007/978-3-030-42097-0_4
} 
in the system of material and spiritual culture. The bicentenary of the birth of Karl Marx took place in 2018, and his ideas and theories still have plausibility, credibility, and relevance as tools to analyze and extrapolate from the situation today. Thus, it is relevant to consider their implications and application to the most transformative technologies of the present day.

Marx considered man's practical activity as the background of his specific attitude to the world (both natural and social). He wrote in "Economic and Philosophic Manuscripts of 1844" that man is not a product of circumstances and upbringing and we should not consider our mind as a passive sensation recipient. According to him, nature is a "man's inorganic body with which he must remain in continuous intercourse if he is not to die" [1, p. 87]. While transforming the world, man creates both a new reality and new conditions of his existence that are not given to him in a ready-made form by nature. He also develops and perfects himself, specifically in his creative abilities. Hence, this results in the actual transformation of the physical world, which can be considered as the foundation of other manifestations of original human activity. Marx stresses that man is an "objective being" and "acts objectively" [1, pp. 92-94]. Further, he defines the way of including man in the natural world and society surrounding him through the active transformation of real objects and phenomena in the process of his praxis. This framework gives some initial guidelines to represent Marx's interpretation of man in all the variety of his relations with the world as a whole.

According to modern epistemological tendencies, the fundamental characteristic of practice as a specific output of man's existence is its openness to objective reality, which always exceeds his abilities to master it. In contrast, there are still limitless human capabilities to develop new ways and means in order to interact with reality. As a result, the basis of the human attitude to the world is the creation of such a system that allows man to construct definite artificial renewable tools and means to influence his reality. He passes these from generation to generation; however, while creating, reproducing, and perfecting this "transformed nature" humanity transforms itself due to the formation and improvement of its appropriate skills and actions.

Marx asserted that the realization of any forms of practical and transformative activity occurs only under conditions of social cooperation [1, p. 95]. It follows that people's attitudes, as subjects of practical activity, to the objective reality that they transform always assume real human relationships as a concomitant. Thus, practice as a philosophical category is formed, reproduced, and developed in the unity of "subject-object" and "subject-subject" relations: it is a manifestation of public activity. A human's self-motivated intellectual evolution in practice is connected with the development of their communication skills and communication culture as necessary preconditions of mastering the external world.

According to the theory of communication, this approach coincides with the information interpretation of the communication process, as can be found in the works of Shannon [2]. Its main characteristic is specific attention to the linear character of communication, i.e., it is an irreversible process. Following the communication paradigm, practices influencing the mass audience intentionally, e.g., mass media, government information, political structures or marketing, are dominant. They have 
various forms of information-based influencing and techniques for manipulation of human consciousness in their foundations.

Hence, communication practice, as with any others, will be always connected with definite forms of perception of the world and a definite level of cognition, focusing on practical achievements and promotion of their further reproduction and perfection. According to Marx, primacy of practice means that the efficacy of its influence on nature, society, and personality is a characteristic of the development of the subject's cognitive activity [1].

Thus, practice as a specific form of human activity in the world possesses a complex system arrangement. It includes the following:

(1) real transformation of the external environment by artificial tools and instruments (subject-object relations);

(2) communication during this transformation (subject-subject relations);

(3) a complex of norms and values (value and goal-oriented structures) that facilitates the targeted practical activity.

\subsection{Modern Epistemology About Subject-Object Relations}

Everything that really exists and is external to the subject, can be regarded as an object of cognition. It can be not only an item, but a whole complex or a system, either natural or ideal.

Any physical thing existing in space and time, any objective and real situation can be considered as an object of cognition. It can be the subject's body, his/her consciousness or personality in general, another person, their consciousness, any cultural items (including books) and their meanings [3, p. 157].

The spectrum of the objects to be studied has significantly widened with time, due to an evolving system of ideals and norms of the cognition process, and this has allowed the discovery of ways to research and master complex, self-regulating systems.

Special attention is currently being paid to discourse as a communication, i.e., verbal communication practice. Alexy [4] separates the following discourse rules, which he identifies as the most important points to understand the rational communication process:

- Any subject who knows a language and is capable of functioning can participate in discourse;

- Any subject can question any assertion;

- Any subject can introduce any assertion into discourse;

- Any subject can express his/her aims, wishes, and necessities.

Such an approach allows the achievement of a consensus due to the overcoming of personal subjective opinions by the participants of a discourse in favor of an 
agreement motivated rationally. Both language and practices outside of language become important. They generate various forms of communication among discourse participants.

As an example of substituting subject-object relationships by the process of observation, it is useful to consider the ideas of the theory of autopoiesis by Maturana and Varela [5]. According to this theory, a human as "a living system" does not just reflect the world surrounding him/her, but constructs the worldview in correspondence with his/her cognitive, existential, and social sets [5]. As an autopoietic system, a human progresses independently while broadening his/her relations with the world. Accordingly, this leads to the appearance of inner and outer relations that then form his/her personal space.

Autopoietic systems have the following features:

(1) Operational insularity-the self-organization process is possible due to feedback based on the system's inner laws: it is not guided from the outside;

(2) Informational insularity - any outer influence should be transformed into an inner cerebral activity because such a system can respond only to inner activity;

(3) Physical openness - there is an exchange of substances and energy with the environment, and its character is defined by the autopoietic system.

A system's inner state forms the subject's idea of the environment. However, there is always an outer observer who could play the role of the subject observed. In fact, this process of changing observers is limitless as there can be no last observer, i.e., an exclusive observation system does not exist. This means that absolute objective knowledge about the world cannot be achieved. Thus, it is possible to conclude that the achievement of some balance between reality and the result of a subject's cognitive activity is impossible in practice: since a subject constructs his/her worldview, everyone has a personal reality. In this sense, a subject does not feel any boundary between their own experience and their conception of reality. Hence, cognition equates to adaptation: an object exhibits something that is correlated with the subject's cognitive activity.

According to the "observation of the second order" theory of Luhmann, observation can consist of characteristics that create a complex system [6]. Cells, organisms, societies, and systems of artificial intellect are able to play the role of an observer. A second-order observation (or an observation of an observation) is different because of the circumstances of its observation, i.e., depending on whether an observer itself has performed it or someone or something has been observing him/her. According to the theory, an observer cannot see itself, i.e., it is not able to recognize itself during the observation. At the same time, however, another observer can see it. In this case, the object has the ability to see the observer and to see what is being observed. Luhmann defines this process as a second-order observation (auto-reflection concept) and believes that it is these conditions that serve as the foundation of epistemology.

The concept of observation allows us to avoid the traditional epistemological terminology that can be found in Aristotle's works, in particular, the subject-object scheme. For example, it is possible to consider the relationships between a system and its environment while observing the system. "Countless discrete systems operate 
inside a man as a condition of his life. They define the operations they implement by means of their own structures, despite being dependent on each other" [6, p. 11]. Thus, this explanation promotes the notion that the world of observation is created in the same way as any other system activities.

Accordingly, the answers to the ontological questions: "what is it?" and "what is its state?" depend on a definite observer, who is restricted by the world of his/her observation. We can say that the observer is similar to some empirical entity that stipulates the selection of him/her as an object by other observers. It is obvious that the subject and the environment in which it acts are interconnected constructively and therefore experience mutual formation in the process of the subject's activity.

It is possible to conclude that nowadays cognition is considered as an active process of a subject's activity. Firstly, cognition is the process of constructing the reality perceived by a subject through his/her cognitive operations, thus explaining why the knowledge that a subject receives, is a construct of the reality rather than of its reflection. According to Apel [7], the subject of perception is now becoming involved in cognitive practice rather actively, as a result of interaction between perception means and objects on the basis of "significant thought". This category requires a symbolic interaction, the nature of which is revealed most strongly in language [7]. There is such a statement in the works of Habermas, where he considers "communicative action": according to him, this helps to overcome a number of antinomies, which have not been overcome by previous concepts of rationality [8].

Thus, the cognition process organizes a subject's inner world model, but it does not solve the problem of how to describe the objective ontological reality. A subject is considered as a part of the world that s/he is going to observe or as a part of some system that is being observed by other observers. Thus, subject and object determine each other reciprocally.

According to the interpretative constructivism theory of Lenk $[9,10]$, the interpretations connecting cognition and action run through all approaches to the analysis of the world and the subject of cognition: "Cognition is an action, but action is an interpretation... Hence, cognition is an interpretation. It means the process of cognition uses the results of the interpretation process or, to be exact, manifests itself in them" [9, p. 18]. Interpretation is not realized only by means of language as it is a more complex process:

We think we might somehow grasp things immediately by language without taking into consideration that these matters are in reality much more complex. Language developed mainly as an instrument for preparing actions which we use in a similar vein like other means and instruments $[10$, p. 3].

According to these ideas, any view of reality depends on theoretical concepts, specifically the linguistic models that dominate in the society concerned. They include fundamental ideas, axioms, formal and linguistic instruments, and so on.

The concepts of how we 'grasp' these 'realities' of different sorts and levels will be one main focus. ...methodologically speaking, we need a systematic approach to the processes of how the phenomena of knowledge and (re)cognition, perception, action and meaning can be analyzed from a systematic point of view [10, pp. 4-5]. 
Hence, interpretation is an activity to create the so-called "mind constructs" which involve both ordinary and scientifically conceptualized structures. This approach allows the making of a model that contains only the aspects relevant to a subject's purposes and its actions. The subject does not care about the model cognized: he/she thinks only of compensating the deviations while trying to achieve the appropriate purpose.

As a result, any perception of reality will depend on theoretical concepts that prevail in the surrounding society, including fundamental ideas, axioms, formal and linguistic tools, etc. Hence, the preconditions to the formulation of modern ideas concerning the possibility of knowing the world are as follows:

1. What a person takes to be the experience of the world does not dictate the concepts which can explain the world.

2. The concepts which can explain the world are products of historically situated interchanges among people.

3. The degree to which a given form of understanding prevails or is sustained across time is dependent on the vicissitudes of social processes (e.g., communication, negotiation, conflict, rhetoric).

According to this new approach, forces and relations of practice co-construct each other. This term, "co-construction", belongs to recent constructivist technology studies, which have rediscovered Marx's idea of social and technical interdependence [11]. Contemporary technology studies offer concepts useful for analyzing these developments and also for identifying what they hide. In this domain, technology is conceived not as a pure product of inventive genius or an application of science, but as a "construction" of social actors. This leaves room for social choice between different designs that have overlapping functions, but better serve one or another social interest. This means that context is not merely external to technology, but actually penetrates its rationality, conveying social requirements into the human practical activity.

According to Sukhodub [12]:

Rationality in modern conditions serves as a method to develop critical thinking that is able to estimate crisis phenomena and to conceptualize the ways of overcoming them in social, economic, political, cultural and other spheres. It helps to make a conversion from authoritarian ideas that function formally in the society to the dialogic mind that is perceptive to 'Others' experience [12, p. 531].

Thus, it is possible to conclude that modern thinking culture is formed as a transition from the postulating mind, which is based on some sustainable content of ideologies prevailing in the society, to the communicating mind, which is founded on the multiplicity of viewpoints and openness of the rational cognition system. 


\subsection{Practice as a Unification of Subjective and Objective Reality}

Practice is the foundation of all forms of human public activity. Its openness to the external world and its possibility to master new layers of objective reality in the process of practical transformative actions suppose an opportunity for regular development of a subject's practical skills, e.g., his/her creative attitude to reality, or participation in various forms of social life. It leads to regular revision and perfection of the fundamental programs, which form the basis of practice. As a result, all the history of mankind, including material and spiritual culture, can be considered as a process of human creative approaches to nature in the form of new programs of practical activities.

According to Hegel, subjective and objective reality contradict each other at the very beginning of the cognition process, as they constitute opposites. The life process starts with the individual necessity "to remove" objective reality that is opposed to it and, thus, "objectify" itself. This can be achieved through a subject's "violence" to an object [13, p. 824]. It is possible to suppose that practice can be taken as a kind of objectification of a subject. Marx writes: "as objective activity everywhere in society becomes one of man's essential efforts, all objects become his objectification, realization of his individuality, his objects" [1, p. 121]. Thus, practice is the unity of objective and subjective aspects of individual activity. It can be represented as a complex net of various acts of object transformations with the "objectification" of a human's essence. Objects from one stage of this activity turn out to be the initial ones for another stage or another activity program.

The structural characteristics of an elementary act of practice can be recognized if the labor process is taken as a pattern. Marx in his work "The Poverty of Philosophy" [14], discussing the cost of labor, reveals its following elements: man with his aims, knowledge, and skills; operations of his rational activity; and objects included in definite interactions in the course of these operations. Paying special attention to the labor object, he considers, that "labour is qualitatively defined by object and object in its turn is defined by specific labour qualities" [14, p. 32].

This pattern can be applied to the structure of practical activity and introduced as the unity of subjective (man with his abilities, aims, and rational actions) and objective (production means, initial materials, products of labor from initial materials) aspects of the cognition process. There are various forms of human practical activity: according to Marx, the initial form of practice that lies in the foundation of other kinds and forms of human life activity, in general, is material production as a way of getting material welfare, which, in its turn, becomes the main driving force of social development. 


\subsection{Technical Activity as a Special Form of Practice}

Forming and developing public relationships is also a necessary form of practical transformative activity: it does not influence the environment surrounding a human, but it involves people themselves and their relationships. However, this form of practice is initially connected with the material production practice. According to Marx, "the way of producing material life defines its social, political and spiritual processes in general" [15, p. 7]. Hence, this view proposes that there is a unified practical activity that includes two aspects: man's attitude to nature and his attitude to himself. It is worth noticing that during public interactions these aspects differentiate further and further since, due to the universal character of public activity, the subject can be both pieces of nature undergoing transformation and people whose "properties" change because of their inclusion in various social subsystems interacting in society as an integrated organism. Studying the first possibility, we can conclude that humankind deals with the human influence on nature, but the second postulated subject concerns the "subjective" character of practice as aimed at the transformation of social objects. From this point of view, humans can be considered as both the subject of practical activity and as its object.

The early stages of social development witnessed the unification of subjective and objective aspects of practical activity. As the labor process became more complex, the operations that had been performed by man started to be materialized. They were carried out as a sequence of influences of one tool on another and after that on the object being transformed. Science as a special form of practice, having more narrow social significance than production or social instances, gained an increasing influence in society. It then turned into a direct production power and a means for control of social processes.

Scientific cognition by itself possesses such qualities as a reflection of existing objects and these can be received or reproduced by different forms of practical activity. It also has projective and constructive functions, i.e., it provides knowledge about the objects being mastered during production and during social activity in the future. To check the validity of the knowledge requires a scientific experiment as a special form of practice: as a rule, this is typically based on production opportunities and human social experience within the current stage of development of society, but it overcomes the contemporary level of entities and foresees future technologies and ways of control of social life activity.

\subsection{Social and Cultural Perspectives of Communication Technologies}

In view of the accelerating pace of technological advancement, it is appropriate to consider ideas about the likely evolutionary paths of technologies that strongly influence society (especially communications technologies) before returning to consideration of the correlations with Marx's concepts. 
At first, it is necessary to understand what the term "trans-science" means. It is often used by participants of international philosophical forums and conferences. According to Weinberg, the trans-science period started with the first A-bomb tests in the middle of the twentieth century. It stipulated the shift from researching nuclear power by some scientists to team projects:

Many of the issues which arise in the course of the interaction between science or technology and society, for example, the deleterious side effects of technology, or the attempts to deal with social problems through the procedures of science - hang on the answers to questions which can be asked of science and yet which cannot be answered by science. I propose the term trans-scientific for these questions... [16, p. 209].

Biological effects of weak radioactive influence on the environment, consequences of applying nanotechnologies to prolong the life expectancy, emergence of virtual reality, creation of artificial intelligence, changes of human ethics under new technological impacts are among such questions.

The main trans-scientific peculiarity is to unite problems from various fields of human knowledge, i.e., it is based on a trans-discipline approach. An outstanding current example is emerging and spreading of the Internet technologies. In comparison with rather rational technological methods, used in the past, modern technologies are able to provide for numerous negative effects due to the availability of mechanisms possessing an opportunity to manipulate the human mentality. Moreover, there has been no comprehensive reflection of their properties so far. So, they might be accepted as the starting point of philosophical deliberations due to the fact that the traditional approach to understanding the technology cannot reflect all the range of arising challenges. As a result, the main question is how all the spectrum of technologies and the social life are changed with penetration of the Internet technologies into absolutely all aspects of human existence.

Scientific knowledge, as viewed from the position of trans-science, is understood as suggesting probable hypotheses, which pass through bifurcation points where the choice of trajectory for further development occurs. This subject of research particularly addresses complex, dynamic systems that include technical, managerial, social, and other levels. Any cognition process turns into a social act, since communication among representatives of different knowledge fields stimulates the emergence of special norms and standards that are not connected with a specific author, but acknowledged as valid by all the scientific community involved in the process. As a result, they become a characteristic of a specific public style of thinking, with a consequential transformation of the communication language, which then acquires a universal character and influences linguistics and linguistic methods. These norms and standards permit cognizance of the complete range of science functions:

- To analyze languages of different knowledge fields.

- To discover "scientific discourse as a net of communications with their mutual intentionality and inter-reflection" [17, p. 496].

- To study natural sciences in the context of communicative relations: it is plausible that this view is also correct for social and humanitarian sciences. 
However, these models have a number of drawbacks. Their acceleration, the extension of their mobility and flexibility and their reduction of local attachment stimulate the arrival of location-independent micro-societies and new social institutions of global communications that can exchange information globally, e.g., in the form of text messages or, more powerfully, as social media. According to Nasarchuk, "man becomes a message generator" [18, p. 69], hence, a message performs a role as the fundamental item of the society, not a human. The whole set of messages, depending on their intention and content, form the lifestyle of a person, a micro-society or a social institution. It does not matter who is a message carrier, because it is the content that gains a dominant significance. This means that its content and its author's (supposed) competence are more important than its sender. Yet, a message and its perception are not always correlated with each other. The example of Internet technologies indicates a conclusion that a sender often knows nothing about his/her message recipient. In turn, the recipient is often not sure that the message has been sent to him/her personally. The recipient thus frequently cannot deduce what should be perceived as the message information as contextualized by some intention, i.e., the objectification of the discussion acquires some fuzziness. Antonovsky and Emelin suggest that "communication on the society level is still possible, but can't form self-adjusting stable successions of messages" [19, p. 106], since the knowledge presented loses its discrete boundaries and metamorphoses regularly.

According to the above conceptions, it is possible to highlight the following social and cultural perspectives of trans-humanism predictions under the influence of communication technologies:

- Forming a new lifestyle.

- Presenting a possibility of the phenomenon of "secularized eternity" in the public consciousness as a result of blurring the borders of reality.

- Changing man's life goals due to his rapidly evolving status as creator of natural and social worlds.

Let us consider the final thesis in detail. An active role of cognition is the most important aspect of the application of these concepts to trans-humanism methodology [20]. It supposes the dominance of activity of the mind in all levels of perception, while nonstructured and nonclassified sensor data are absent.

According to the ideas of trans-science [21], modern technologies will provide new opportunities to create artificial intelligence and, as a result, to realize new social forms and psychosocial processes. The website of the Russian TransHumanism Society [22] cites some of its "radical possibilities" that could follow from the abovementioned trans-science issues and ways of their realization, such as the following:

- Super intellectual machines.

- Extension of life expectancy significantly.

- Transfer of human consciousness into virtual reality (or brain downloading) and similar. 
Trans-humanism manifests itself in three aspects: practical activity; technological achievements and social transformations. Trans-humanism can be considered as a synthesis of discrete doctrines being applied in technological practice, especially in the field of communication technologies. In this conception, a human being is substituted by a virtual existence, i.e., there is the potential elimination of anthropocentrism principles, which were laid in the foundations of traditional humanism and traditional science.

Thus, the exploration of trans-humanism issues needs to be coordinated with the "stable development" conception [23], which can be understood as the necessity of the immediate protection of the environment, on the assumption of further convergence of natural and humanitarian sciences aimed at getting a more comprehensive understanding of a viable forward path. This approach raises a question concerning the boundaries of man's constructive activity, its involvement, and correspondence to the real world. A human being is becoming more and more "technological" with the evolution of communication technologies; however, s/he doesn't stop being sentient: the human, its body and consciousness turn into an integral part of complex eco-, sociocultural, and socio-technical systems [24].

In the context of the developing ecological and humanitarian crisis, the problem of the human future can be considered as a task of preventing the degradation of human and natural systems, achieving co-evolution of science and society, and forming a civilization based on stable evolution by means of searching out sensible answers on topical matters: this correlates with a comprehensive worldview outwith trans-humanism. Communication technologies have a great potential to dominate these issues and define future perspectives of not only science, but the whole of the development of civilization. They can be both production tools and the final product of human fabrication activity. That is why they are becoming more and more important components of the production process, defining its character and content (e.g., "Industry 4.0" [25]). Communication technologies require a range of specific skills from their participants and as a result, imply the dialectic unity of material artifacts on the one hand and human skills and experience on the other hand.

\subsection{Extrapolation into the Future}

The development and introduction of new technologies have led to the emergence of a new sociocultural reality that raises new ethical issues. They are closely connected with the realization of various projects, e.g., complete description of thinking processes and perception of reality by the human brain; the slowing down of aging processes; the opportunity of human organism rejuvenation; the development of brain/brain or brain/computer interfaces; the creation of robots and other devices possessing at least partial individuality; and similar speculations. Ethical problems arise from the realization of the above projects and the ethical principles that are conventionally followed nowadays will be transformed. Development and 
penetration of these new technologies will provoke a cultural effect that is likely to see the intensification of some ethical values and the devaluation of others.

For example, the future achievement of neurointerface technology would lead to the unification of human and machine on a qualitatively new level. It could change the level of virtualization of the human mind and social relations. Penetration of virtual technologies into human sensibility will create the situation of "hybrid reality", which could obliterate distinctions between man's virtual personality and his physical localization in a body. However, the current virtual world of social networks, and especially social media, leads to egocentrism and the human's preoccupation with itself and its thoughts: the result of this can be the loss of relationships between the human and reality. For this reason, discussion of change of the spatial conception concerning the physical boundaries of interpersonal communication and identification is very desirable. This change will involve a reconsideration of the human presence in the communication environment: whether it should be treated in both real and virtual forms simultaneously. Such an approach indicates a potential trend toward a completely new phenomenon of human existence: the boundary between real and virtual exists rather clearly nowadays.

Thus, sociocultural perspectives of the current development of communication technologies include the following:

- The evolving appearance of a new lifestyle.

- Introducing a phenomenon of "secularized eternity" in public consciousness;

- Changing the meaning of human life in a substantial way as humans will be able to feel themselves to be creators of their world.

Marx died in 1883. The telephone was invented in 1876, although the practical deployment of the telegraph dates from 1838. Thus Marx was alive at the beginning of near-instantaneous electrical communications, although the means of propagation of ideas most familiar to him would have been printed works: books, newspapers, and broadsheets. Extrapolation of his ideas to the circumstances of the present day must, therefore, be seen in this light. For him, the industry would have meant the making of hardware products and the concept of the "knowledge economy" would have been difficult to embrace: it is significantly different from material production as a way of getting material welfare (see Sect. 4.3, above). On the other hand, Marx's assertion "the way of producing material life defines its social, political and spiritual processes in general" (Sect. 4.4, above) represents a more information-oriented view and his view that the realization of any forms of practical and transformative activity occurs only under conditions of social cooperation (Sect. 4.1, above) correlates closely with modern concepts of social media and co-production of media artifacts.

\subsection{Conclusions}

The philosophical exploration of social and cultural results of current technological development is becoming more and more topical. Today there is a real necessity to bring out the distinctive features of these technologies and to analyze their impact 
on social reality. It is also very urgent to consider a new approach to humanism, as still understood traditionally, to clarify transformations of social values and the meaning of human life in the perspective of these developments, to study new cultural stereotypes emerging nowadays under the influence of communication technologies and emerging so-called "virtual reality", social media, and artificial intelligence.

Latour demonstrated the relation between technology and society [26] and the theme of democratization of technology has recently begun to receive the attention it deserves. As Latour has argued, the exclusion of technology from the social scientific concept of society is untenable. But once technology enters the picture, the issue of rationality appears in a new guise. It was Weber who introduced the concept of rationalization to explain many of the processes Marx had earlier identified as central to modernity [27]. Whereas in Marx's works such processes were examined as potentially opposing (capitalist or socialist), Weber argued that they were the same for all modern societies. When there is a strong focus on technologies as there is today, a basis for questioning Weber's simplification emerges again. It is clear that the modern world does not provide a unified view on the question of whether mankind is able to get a single homogeneous outcome to both technological and social development. The traditional practice activities as highlighted by Marx are blurring more and more as there is no sharp division between objective reality and the subjects of practical activity. The scheme "object-objective-practical activity-subject" as the foundation of scientific cognition and the criterion for the correspondence between knowledge and reality introduced by Marx has undergone a number of transformations in modern epistemology. Communication technologies with their new sociocultural reality erase differences between material and nonmaterial, nature and culture, theoretical and practical, etc. [26]. We do not need them anymore as the transition to "hybrid reality" and trans-humanism due to the equal interaction of living objects, social structures, theories or scientific-research programs, etc., generates a network consisting of a number of active elements. Its main characteristic is their collective actions. The coordination of their functioning in the network occurs due to the connections among elements, which makes all components interact.

It is possible to conclude that there is a special meaning in these circumstances for such a form of practice as technical activity in the field of communication, and the analysis of Marx continues to give useful insights. This can be directed to the creation of not only material values and artificial environments, but also thinking, cultural, and cognitive processes.

\section{References}

1. Marx, K.: Economic and Philosophic Manuscripts of 1844. Works, Marx, K., Engels, F., vol. 42, pp. 43-174. Publishing House of Political Literature, Moscow (1974) (in Russian). English edition: Prometheus Books, New York (1988)

2. Shannon, C.E.: A mathematical theory of communication. Bell Syst. Tech. J. 27, 379-423, 623-656, July, October (1948) 
3. Lektorsky, V.A.: Classical and Non-classical Epistemology, 256 pp. Editorial URSS, Moscow (2001) (in Russian)

4. Alexy, R.: Legal documentation as rational discourse. Russ. Yearb. Law Theory 1, 446-456 (2008) (in Russian)

5. Maturana, H., Varela, F.: Der Baum der Erkenntnis: Die biologischen Würzeln des menschlichen Erkennens, 217 pp. Scherz, Bern, München (1987). English edition: The Tree of Knowledge: The Biological Roots of Human Understanding. Shambhala Publications, Boulder, Colorado (1992)

6. Luhmann, N.: Erkenntnis als Konstruktion, 74 pp. Benteli, Bern (1988)

7. Apel, K.-O.: Types of rationality today: the continuum of reason between science and ethics. Rat. Today 307-340 (1979) (Ottawa)

8. Habermas, J.: Aspects of rationality of action. Rat. Today 185-204 (1979) (Ottawa)

9. Lenk, H.: Handlung als Interpretationskonstrukt: Entwurf einer konstituenten und beschreibungstheoretischen Handlungsphilosophie: Handlungstheorien interdisziplinar, pp. 18-317. Karl Alber Verlag, München (1978)

10. Lenk, H.: Grasping Reality: An Interpretation-Realistic Epistemology, 282 pp. World Scientific Publishing Company, Singapore (2003)

11. Feenberg, A.: Marxism and the critique of social rationality: from surplus value to the politics of technology. Camb. J. Econ. 34(1), 37-49 (2010)

12. Sukhodub, T.D.: Rationality in philosophical tradition and modern culture: the problem of non-incumbency. In: Kiyashchenko, L.P., Stepin, V.S. (eds.) Post-Non-Classics: Philosophy, Science, Culture, pp. 519-538. Publishing House "Mir", St. Petersburg (2009) (in Russian)

13. Hegel: Science of Logic, 912 pp. Publishing House ACT, Moscow (2018) (in Russian). English edition: Prometheus Books, New York (1991)

14. Marx, K.: The Poverty of Philosophy, 160 pp. Publishing House “马”, Moscow (2017) (in Russian). English edition: International Publishers Co., New York (1999)

15. Marx, K.: A Contribution to the Critique of Political Economy. Works, Marx, K., Engels, F., vol. 13, pp. 1-167. Publishing House of Political Literature, Moscow (in Russian) (1959). English edition: Lawrence and Wishart, London (1969)

16. Weinberg, A.: Science and trans-science. Minerva 10, 209-222 (1972)

17. Ogurtsov, A.P.: Philosophy of Science: XXth Century: Concepts and Problems, vol. 1, 744 pp. Publishing House "Mir", St. Petersburg (in Russian) (2011)

18. Nasarchuk, A.V.: Net society and its philosophical understanding. Russ. Stud. Philos. 7, 61-75 (2008) (in Russian)

19. Antonovskiy, A.Y., Emelin V.A.: Informational society and the technology of adaptation to its structure. Epistem. Philos. Sci. XXXI(1), 90-107 (2012) (in Russian)

20. More, M. Transhumanism: Toward a Futurist Philosophy. Originally published in Extropy \#6 (1990, revised 1996). https://www.scribd.com/doc/257580713/Transhumanism-Toward-aFuturist-Philosophy

21. Danielyan, N.V.: Internet technologies and trans-science: orientation for future. In: RPTSS2017-International Conference on Research Paradigms Transformation in Social Sciences, pp. 246-253. Future Academy, UK (2018). https://doi.org/10.15405/epsbs.2018. $02.28 /$

22. Russian Transhumanist Movement. http://www.transhumanism-russia.ru/

23. Los, V.A., Ursul, A.D.: Stable Development, 254 pp. Publishing House “Agar”, Moscow (2000) (in Russian)

24. Danielyan, N.V.: Scientific Rationality. Publishing House MGOU, Moscow (2010)

25. Lasi, H., Fettke, P., Kemper, H.G., Feld, T., Hoffmann, M.: Industry 4.0. bus. Inf. Syst. Eng. 6, 239-242 (2014). https://doi.org/10.1007/s12599-014-0334-4

26. Latour, B.: On recalling ANT. In: Law, J., Hassard, J. (eds.) Actor Network Theory and After, pp. 15-26. Blackwell, Oxford (1999)

27. Weber, M.: Gesammelte Aufsätze zur Wissenschaftslehre. Mohr, Tübingen (1968); Wirtschaft und Gesellschaft, Bd. 1. Mohr, Tübingen (1956) 
Open Access This chapter is licensed under the terms of the Creative Commons Attribution 4.0 International License (http://creativecommons.org/licenses/by/4.0/), which permits use, sharing, adaptation, distribution and reproduction in any medium or format, as long as you give appropriate credit to the original author(s) and the source, provide a link to the Creative Commons license and indicate if changes were made.

The images or other third party material in this chapter are included in the chapter's Creative Commons license, unless indicated otherwise in a credit line to the material. If material is not included in the chapter's Creative Commons license and your intended use is not permitted by statutory regulation or exceeds the permitted use, you will need to obtain permission directly from the copyright holder.

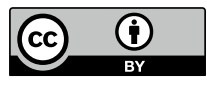

